\title{
SOCIALIZAÇÃO DO CONHECIMENTO SOBRE CRIAÇÃO DE ABELHAS EM COMUNIDADE DE AGRICULTURA FAMILIAR
}

\section{SOCIALIZATION OF KNOWLEDGE USING BEEKEEPING IN COMMUNITY OF FAMILY AGRICULTURE}

\author{
Maria Cristina Affonso Lorenzon ${ }^{1 *}$, Carina de Oliveira $^{2}$ e Maria Duringer Lima ${ }^{3}$ \\ ${ }^{1,2}$ Instituto de Zootecnia, Universidade Federal Rural do Rio de Janeiro. \\ ${ }^{3 .}$ Instituto de Agronomia, Universidade Federal Rural do Rio de Janeiro. \\ * Departamento de Produção Animal, Instituto de Zootecnia, Universidade Federal Rural do Rio de \\ Janeiro, km 7, Rodovia 465, Seropédica, 23890-000. E-mail: lorenzon@ufrrj.br
}

\section{Resumo}

Há premência em se estabelecer projetos de uso sustentável como instrumento de pressão geopolítica para proteção dos recursos naturais e das comunidades que vivem a partir destes. Objetivando-se a conservação da Floresta Atlântica e de sua agricultura familiar, este artigo avalia a experiência de se implementar a meliponicultura, criação de abelhas sem ferrão, em duas comunidades rurais. Duas estratégias foram organizadas a partir da inclusão ou não da escola fundamental, como centro de atividades do projeto para atender as comunidades. Avaliou-se qual foi a melhor estratégia para se alcançar à socialização do conhecimento e integrar a comunidade ao projeto. As relações culturais, políticas e econômicas entre produtores e o projeto são discutidas no escopo do artigo, inclusive aquelas para sobrepor as dificuldades presentes.

Palavras-chaves: educação ambiental, conservação natural, extensão rural, abelha

\begin{abstract}
For pressing political actions it might be profitable to establish and to test sustainable projects for protecting natural resources and human communities who depends on them. As a goal to protect the Atlantic Rainforest and its tradicional familiar agriculture, this article presents the experiences about the relationships of the two rural communities when stingless beekeeping was promoted. In order to involve the communities during the establishing of the project, two strategies were used, which considered or not the elementary school as a central point to spread the social and culture activities. It was evaluated which strategy was effective to promote the social knowledge and to join the community into the project. The social, cultural, economic relationships among producers and the project are discussed and also aspects to overcome the dificulties.
\end{abstract}

Key words: sustainable use, environmental education, natural conservation, rural support, bee 


\section{Introdução}

$\mathrm{O}$ avanço tecnológico ensejado pelas mudanças nos processos de trabalho e produção de conhecimento afeta a prática social. O cidadão trabalhador passa a configurar múltiplos padrões de sociabilidade e de subjetividade, trazendo a exigência do desenvolvimento de novas competências, tendo em vista a emergência constante de novos conhecimentos e a imprevisibilidade de uma colocação futura na sociedade.

Tais competências constroem-se nos diversos espaços da aprendizagem que configuram a trajetória cotidiana de todos esses cidadãos. Compete à escola possibilitar a construção de lastros de conhecimentos e habilidades genéricas, notadamente no desenvolvimento de suas atividades profissionais, para as quais são exigidas atualmente.

A construção do conhecimento a partir de projetos na comunidade pressupõe um objetivo que dá unidade e sentido às várias outras atividades, o mesmo se aplica ao seu produto final, que pode assumir formas específicas, dentro de uma comunidade e, ou integradas, para várias comunidades. A inserção de projetos na comunidade cria também instrumentos facilitadores do cumprimento das exigências pedagógicas. A participação de escolas em projetos da comunidade permite envolver os alunos em uma construção de conhecimento integrada às práticas vividas. Nessa perspectiva, o aluno deixa de ser apenas um aprendiz do conteúdo de uma área de conhecimento qualquer, ele se desenvolve em uma atividade real e, nesse processo constrói sua autonomia. Assim, ao se apropriar, ao mesmo tempo, das conquistas das gerações precedentes, se forma como sujeito cultural e se prepara para novas conquistas.

$\mathrm{Na}$ atualidade, a biodiversidade se configura como tema crítico frente à construção social de um problema mundial do meio ambiente; em torno dela se centralizam debates entre a mercantilização da Natureza e da sobrevivência humana, e se expressa em conflitos de uso e de escolha pelas sociedades (TANIZAKI-FONSECA et al., 2000). Trata-se de uma temática complexa que envolve a interdisciplinaridade e dificuldades inerentes a articulação dos saberes. Exige uma mudança profunda de pensamento em relação à Natureza, assinalando o fim das verdades absolutas e abrindo espaço para a relatividade do real e suas incertezas, em novas formas de saber. Tratar de projetos que envolvem a conservação da Natureza exige cautela e reflexão. Para Becker (2001), antes ou, simultaneamente à implementação de estratégias de conservação, é necessário sensibilizar as instituições locais, as associações, as populações envolvidas, e favorecer a negociação entre os diferentes grupos de interesse, para alcançar um compromisso 
sobre sua proteção e sua utilização sustentável; o projeto deve construir um bem coletivo (GUIMARÃES, 2005; AUBERTIN et al., 1996).

A região da Costa Verde do estado do Rio de Janeiro é considerada um dos mais exuberantes cenários naturais, a sua economia está voltada para a exploração do turismo ecológico e pela presença, quase que configurativa, da agricultura familiar que sobrevive à custa de suas tradições. É uma região que apresenta muitos fragmentos da floresta Atlântica, sendo este bioma reconhecido como uma das 34 áreas do planeta, com maior biodiversidade e taxa de endemismo de espécies, em processo de degradação e extinção (Hot Spots) (MAYERS et al., 2000). O estado do Rio de Janeiro possui cerca de $17 \%$ da cobertura original da floresta Atlântica (ROCHA et al., 2003), que vem sendo constantemente ameaçada pela ocupação humana.

O binômio sustentabilidade e educação ambiental são suportes para projetos de conservação para biomas como a floresta Atlântica. Dentro desta premissa destaca-se a criação de abelhas silvestres, que vem sendo adotada com sucesso em vários biomas brasileiros para melhor atender a subsistência da população humana, enquanto diminui a pressão antropogênica sobre áreas protegidas sob o escopo de atividade de uso sustentável (NOGUEIRA-NETO, 1999, KERR et al. 1997, 2001, ALVES DOS SANTOS, 2003), ora ligados a comunidades (VENTURIERI, 2003), ora às escolas (SANTOS DA SILVA et al. 2001).

A partir da implementação de um projeto de uso ambiental, com foco na criação de abelhas silvestres este trabalho objetivou avaliar a proposta interdisciplinar de partilhar conhecimentos interativos entre educandos e a comunidade, para aprimorar suas capacidades de articular os diversos saberes e contextualizá-los em suas ações práticoreflexivas.

\section{Metodologia na Comunidade Rural}

O estudo foi realizado janeiro a dezembro de 2007 no município de Angra dos

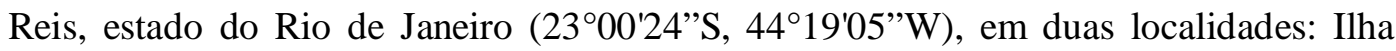
Grande (parte insular) e Ariró (parte continental). Angra dos Reis apresenta tipo climático tropical úmido, segundo Köppen, com temperatura do ar média anual de $25,5^{\circ} \mathrm{C}$, pluviosidade de $2240 \mathrm{~mm}$ (CNAAA, 2005). A região é típica de vegetação de floresta tropical (Mata Atlântica), com topografia acidentada, que favorece sua preservação. Ariró é uma área residencial rural de Angra com casas de campo e pequenos produtores agrícolas e cercada por fragmentos de floresta densa. A Ilha 
Grande é um fragmento do maciço litorâneo de aproximadamente $190 \mathrm{~km}^{2}$, que faz parte do conjunto de ilhas da Baía da Ilha Grande (OLIVEIRA, 2002), sendo a maior ilha do estado. Apresenta muitas moradias e cerca de 3000 pousadas revelam sua aspiração turística (VALLEJO, 2005).

O projeto fundamentou-se na implantação da meliponicultura na região, criação de abelhas sem ferrão (Apidae: Meliponina), que pode ser uma alternativa sustentável viável para as comunidades humanas que vivem do turismo ecológico da floresta Atlântica. O grupo silvestre de abelhas sem ferrão pertence a este bioma. A criação adotou espécies silvestres de abelhas mansas e produtoras de mel, conhecidas como espécies-bandeira, que por serem carismáticas para o público, podem ser utilizadas como propaganda para proteger determinada área e outras espécies de abelhas menos popularizadas, enquanto permite a inclusão social e econômica do projeto junto à comunidade alvo.

A criação de abelhas silvestres foi instalada obedecendo-se duas estratégias de implantação: a) comunitário - com a criação localizada fora da escola, com a apresentação de atividades esporádicas do projeto na rede municipal de ensino, distintas de reuniões com outras associações da comunidade; b) escola-comunidade - com a criação localizada dentro da escola, com apresentações esporádicas em uma escola da rede municipal de ensino fundamental, para atrair os produtores rurais. Em ambas as estratégias foram feitas reuniões com o corpo docente e as Secretarias de Educação, Agricultura e Meio Ambiente locais, para moldar e apoiar a implementação do projeto nas comunidades.

Foram implantados dois meliponário-escola, um para cada estratégia. O projeto que atendeu a estratégia comunitário, externo `a escola, foi localizado em Abraão (Ilha Grande), com 18 colmeías de Tetragonisca angustula (abelha jataí), em uma organização não governamental, de fácil acesso ao público. O outro meliponário foi localizado em Ariró, que atendeu a estratégia escola-comunidade, instalado dentro do pátio da escola, com 12 colmeias de Melipona quadrifasciata (abelha mandaçaia) e sete colmeias de abelhas jataís. A construção dos meliponários foi realizada com a ajuda de produtores de cada local de estudo. Nas duas localidades foi promovida a inauguração do projeto para atrair a comunidade. Após a inauguração do meliponário, as revisões das colmeías foram rotineiras, momento em que se procurou motivar a participação da comunidade, dentro do princípio "aprendendo-fazendo". 
As escolas que participaram do projeto foram de ensino fundamental ( $1^{\mathrm{a}}$ a $8^{\mathrm{a}}$ série $)$, os alunos apresentavam faixa etária entre 6 e 12 anos. Na estratégia comunitário foram visitadas oito escolas na Ilha Grande, que apresentavam cerca de 400 estudantes; na estratégia escola-comunidade, o projeto se estabeleceu na escola de Ariró, que apresentava cerca de 80 alunos. Nas duas estratégias, se mobilizaram alunos, professores, técnicos, agricultores e outros tipos ocupacionais da comunidade, tendo como eixo o desenvolvimento do projeto. Aplicaram-se atividades pedagógicas, integrando o tema abelha - meio ambiente, a saber: teatrinho, exposições em murais, exposições orais no campo e em sala de aula, aliadas à exploração lúdica. Paralelamente, realizaram-se visitações à criação de abelhas, oficinas para produtores, professores e alunos, de modo a motivar a participação integrada dos mesmos ao projeto de criação de abelhas silvestres. As oficinas eram de curta duração (4 horas), realizadas no campo e era composta por material pedagógico específico, seguido pela prática para fixação

Para avaliar o desenvolvimento e pespectivas do projeto na comunidade, aplicouse questionário sobre o interesse em criar racionalmente abelhas e na conscientização ecológica, para o conhecimento do público-alvo. Igualmente foram pontuadas as ações pedagógicas nas escolas, através da análise de comportamento, com a presença de um observador durante as exposições.

\section{As comunidades}

Em Angra dos Reis se destacam como atividades sustentáveis o artesanato e o turismo. Não há qualquer projeto agrícola de cunho conservacionista, deixando à margem as famílias rurais. O mercado livre demonstra a limitação do comércio local de seus produtos: há poucos produtores, há produtos sem fiscalização, as embalagens são pouco atrativas e recomendáveis, não há empresas nem associações vinculadas aos produtores. Os produtos da abelha aparecem de forma escassa e, muitos são originários de outros estados. Apesar do caráter rural da região verificou-se a ruptura das novas gerações com a agricultura, atitude que conduz à construção de uma nova relação com a terra e todo o meio ao redor.

Nas localidades acompanhadas, somente Ariró tem autorização para a produção agrícola. De acordo com a Secretaria de Agricultura do município foram cadastradas 68 pessoas diretamente ligadas às atividades de agropecuária, silvicultura e exploração florestal; sendo 47 assalariados; e na pesca estão envolvidas 45 pessoas, sendo 11 
assalariadas. A comunidade faz uso de técnicas alternativas para o combate de doenças e pragas agrícolas, como caldas com fumo, sabão, cinzas, dentre outras. As principais culturas são: banana (96\%), mandioca (92,3\%), milho (80,8\%), jambo $(69,2 \%)$ e laranja $(65,4 \%)$. Quanto à criação animal, a mais comum é a criação de galinha caipira (50\%), alimentadas com milho e restos de alimento. Dos entrevistados (40) apenas um cria abelhas, com apenas uma colônia de abelhas sem ferrão (abelha jataí). Também são comuns atividades de caráter extrativista, como é a do "palmito jussara"; a extração de mel de enxames localizados na mata e caça de animais silvestres, como "lagartos", "preás" e "capivaras". Na região, as abelhas silvestres são conhecidas como "mandaçaia", "oropa", "jati-pernilongo" ou "jataí", "mirim”, "cachorro" ou "arapuá". $\mathrm{Na}$ Ilha Grande dedicam-se a organização da moradia, do jardim, mas a maioria utiliza plantas exóticas para ornamentação. Não escassa informação sobre o uso de plantas nativas para consumo e ornamentação. O lixo não é acumulado e retorna ao continente.

A maioria dos moradores são proprietários de suas terras (62,5\%), consomem mel $(57,5 \%)$, dizem ter bom conhecimento sobre produção de mel $(72,5 \%)$ e têm interesse em criar abelhas sem ferrão (47,5\%). Apenas 5\% dos entrevistados reconhecem a importância das abelhas como polinizadores de espécies florais.

Os escassos relatos de experiências sobre a criação artesanal de abelhas é um dado preocupante em se tratando de sistema tradicional ligado à conservação da biodiversidade (RODRIGUES, 2001). A falta de fomento, informação e divulgação sobre essa criação e seus produtos, a coloca à margem do panorama econômico regional e constitui um entrave para a sua implementação, por depender de recurso contínuo para suprir sua manutenção.

Os produtores se mostraram carentes por atividades rurais, e atualmente, dependem dos serviços urbanos, para obter remuneração. No geral, o tema abelha e meio ambiente despertou interesse e curiosidade nas comunidades, mas a magnitude do interesse da informação está mais voltada para a criação da abelha exótica (apicultura), conhecida popularmente como "oropa" ou africana, do que com a artesanal com abelhas silvestres. O comportamento de docentes e estudantes variava entre temor e interesse. As informações foram enfáticas em torno de acidentes devido à ocupação das abelhas exóticas em muitas áreas públicas, fato que no Brasil se estabeleceu por décadas (PEREIRA \& CHAUD-NETTO, 2005). Os relatos da comunidade sobre a predação de enxames e outros animais para obter alimento é uma atitude que fortalece seu perfil de extrativista. 


\section{A experiência de implementação do projeto na comunidade}

Uma vez introduzido o projeto de abelhas sem ferrão silvestres e seu papel ecológico, verificou-se que a maioria dos participantes desconhecia esta modalidade de criação e as espécies recomendadas de domínio da floresta Atlântica, o que evidencia o quanto a cultura indígena está longínqua da atual. As espécies de abelhas atraíram fortemente toda a comunidade, pela sua mansidão, organização e facilidade de manejo. As revisões dos enxames eram de euforia e surpresa, ficavam preocupados com a delicadeza dos enxames e a coleta de mel era sempre a maior indagação..

Nas escolas, as apresentações do projeto ganharam expressiva participação dos estudantes e parcial dos professores, que não se envolveram com o tema abelha e meio ambiente e houve baixa mobilização para se integrar às atividades práticas com os alunos. Este resultado ressalta que a aplicação da educação ambiental é extraordinariamente precária e fragmentada (RODRIGUES, 2001). As atividades lúdicas aplicadas nos alunos foram retratadas em desenhos e mostram a mudança da percepção dos alunos com relação às abelhas; os desenhos revelam a integração da abelha com a Natureza e a representação, de forma figurativa, da relação inseto-flor, indicativo de polinização das plantas pelas abelhas (Figura 1), comumente tema difícil de ser introduzido para adultos, que consideram, que a principal função das abelhas é a de produzir mel.
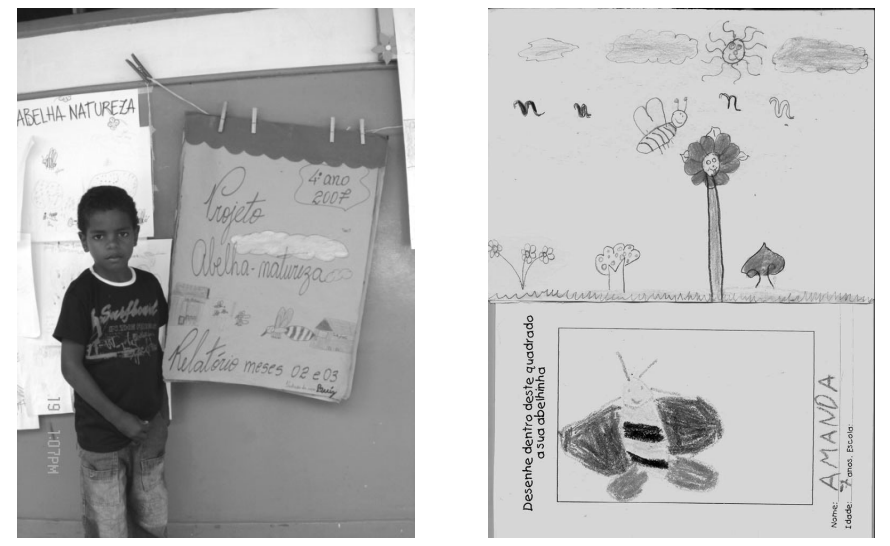

Figura 1. Expressão lúdica de estudantes do ensino fundamental sobre o tema abelha e meio ambiente. Ilha Grande e Ariró, ERJ.

A instalação do meliponário-escola (Figura 2) atraiu grandemente a atenção da comunidade, possibilitou a visita de estudantes, residentes, turistas e a mídia, que 
passaram a fazer visitar constantes para conhecer a criação de abelhas (Figuras 3 e 4). Na Ilha Grande, os guias turísticos oficiais se interessaram em utilizar a criação em seus passeios e foram instruídos sobre a necessidade de preservação das abelhas dentro das áreas de reserva e seus entornos. Atualmente, alguns criadores cobram uma taxa módica por pessoa para a vistação, para garantir certa rentabilidade.

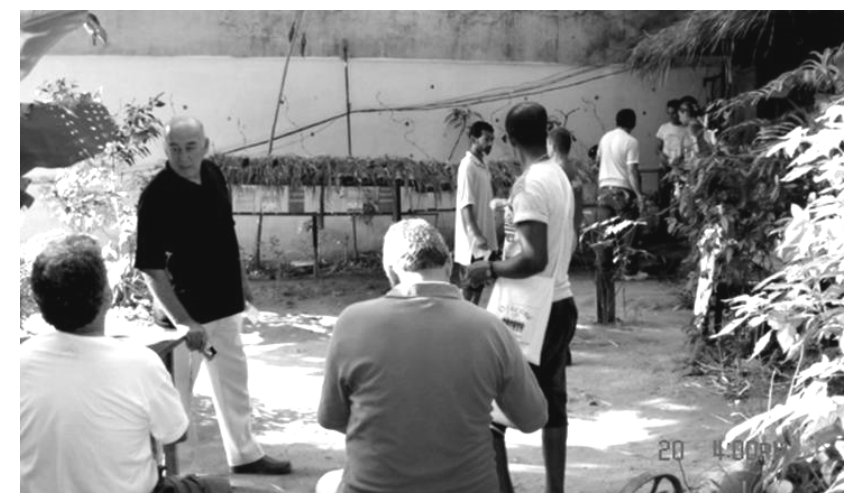

Figura 2. Visita da comunidade ao Meliponário-escola de Abraão, Ilha Grande, ERJ.
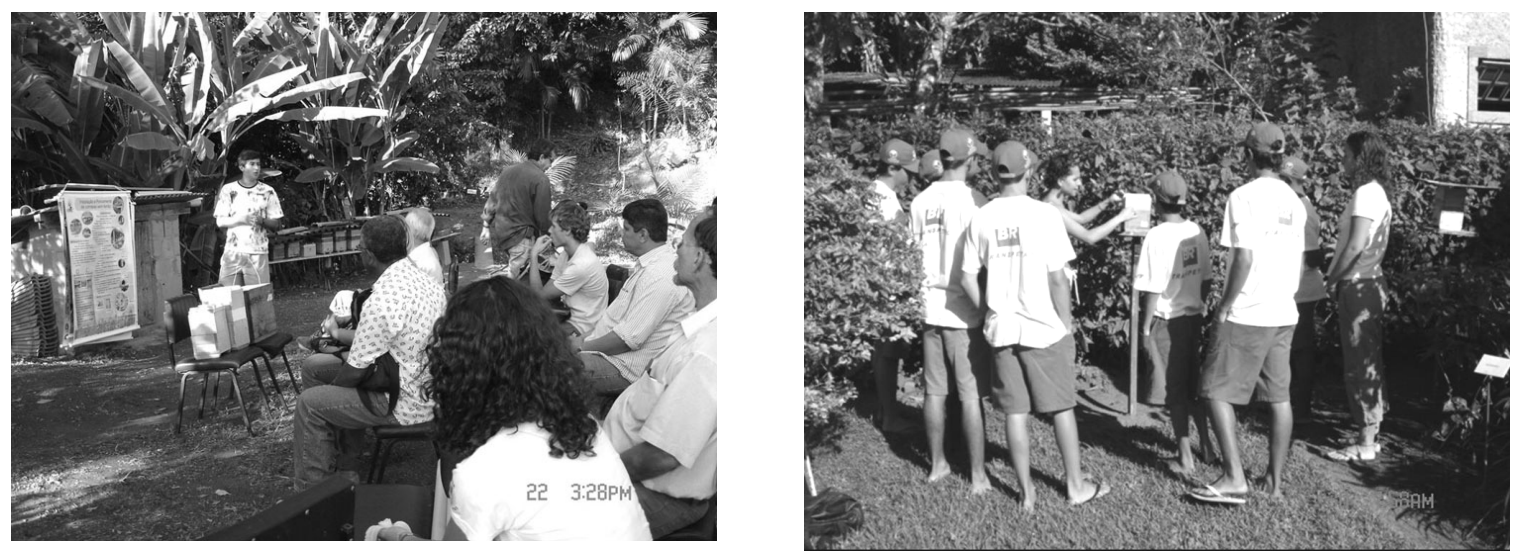

Figuras 3-4. Revisão de colméias de abelhas sem ferrão com a participação de estudantes e de outros interessados. Angra dos Reis, ERJ

Sob a ótica das duas estratégias aplicadas, a mesma temática do projeto culminou em variações de resposta. Ao se implementar a criação dentro da escola a participação estudantil foi a mais expressiva, com acanhamento dos produtores. A adoção da criação de abelhas fora do âmbito da escola permitiu maior adesão, motivação e mobilização dos produtores e participação temporária das escolas. Este resultado evidencia uma realidade social e educacional muito diversificada, sintomas que acarretaram um 
deslocamento momentâneo no aprendizado do tema do projeto. Progressivamente, este quadro foi tomado por paradigmas pluridisciplinares, delineando questões ecológica, econômica, social, etc, centralizado em atividades desenvolvidas e produzidas com criatividade pela comunidade, seja de forma integrada ou não. A postura dos participantes foi sempre favorável à proteção do meio ambiente e partilharam suas experiências de forma espontânea, mas revelaram dificuldades em assumir a integração nestas atividades e em enfrentar os seus desafios como proposições desafiadoras relativas à proteção da floresta Atlântica, que convivem.

Politicamente, o projeto teve resultados diferenciados nos locais de estudo. Na Ilha Grande, o apoio logístico coube ao órgão gerenciador de áreas de conservação, uma vez realizado o intercâmbio com a comunidade, imediatamente esta se mobilizou para atrair novos representantes. Em Ariró, a inauguração do projeto movimentou fortemente o ego político local pela propriedade do projeto, mas a concessão de seu apoio logístico foi fundamental para atrair os produtores à implementação do projeto. Nesta localidade, a rivalidade política, ora atuante entre os representantes dos órgãos governamentais, prejudicou o estabelecimento do projeto ao declinar seu apoio e desestimular muitos grupos de produtores. Este fato prenuncia o antigo paradoxo: de um lado a escola, associada à idéia da razão e progresso, de outro lado, os impasses sociais, onde se acumulam as tecnologias em detrimento da maturidade política (Freire, 2004).

O fomento cultural sobre a temática do projeto através de oficinas permitiu disponibilizar informação suficiente aos produtores. As oficinas realizadas a campo, com a teoria, acompanhada da prática mantinham os produtores cativos ao projeto. Ao se partilhar o conhecimento a partir da escola, que representa importante elo para atrair a comunidade, recomeda-se que se estratifique o público-alvo, já que os interesses foram distintos: o dos estudantes é acadêmico e o dos produtores é prático, é força de trabalho. A motivação dos estudantes foi tão alta durante as oficinas na escola que contribuiu para afastar os produtores, cujo interesse no conhecimento se tornou tênue, por almejarem imediata praticidade; equivocadamente os produtores consideraram que o conhecimento permite apenas escassa expectativa de renda. Assim, primeiramente, há necessidade de se utilizar os produtores diretamente no sistema produtivo acompanhado de parte dos estudantes.

A construção de um projeto vivo, com os produtores foi uma oportunidade inovadora e inédita para a estratégia na escola em estudo, cuja relação estreita com os pequenos produtores ainda é tenra e inovadora; até aquele momento a escola somente 
tratava da educação dos filhos dos produtores, a proposta visava atrair a comunidade com um todo. Provavelmente, experiências bem sucedidas pelos produtores possibilitassem maior confiança do sistema escolar que adotou o projeto. A meta do projeto em envolver os produtores às escolas, com o propósito de colaborar na conscientização ecológica dos estudantes carece de funcionalidade e persistência. A implementação da visão de aplicação de projetos, conduzida pela visão transdisciplinar na educação pede uma profunda e contínua reflexão e subseqüentes tentativas de implementação concreta (LEITE, 1992).

Os produtores não colocaram barreiras para a adoção desta criação, porém por ser atividade simples, de baixo investimento, houve claro desinteresse, a comunidade parece almejar lucros altos e imediatistas. A maioria vive do turismo, tem bom padrão de vida e oportunidades de emprego parecem ser acessíveis na localidade. O real sentido da sustentabilidade para a comunidade local é abstrato e o interesse pelo futuro é superficial. Esta é outra razão que justifica a implementação de projetos de uso sustentável nas escolas, que enquanto desafiadora, resolve problemas e progride, e vai além da economia e atinge um público maior e heterogêneo.

Os dirigentes das escolas reconheceram que há necessidade de um compartilhamento do programa escolar com as questões ecológicas e programas para sustentabilidade, de modo a favorecer a socialização deste conhecimento. Através de ações contínuas será possível conciliar a meliponicultura às atividades escolares, desde que haja um interesse real da escola em executar o projeto como atividade integrada com a comunidade. Resta acreditar que a escola, que comumente se abriga em um acúmulo progressivo de conhecimento, repleto de promessas, possa adotar o projeto como proposta desafiadora para o ambiente que vive.

Em que pesem estas ambigüidades, a educação ambiental emerge hoje como uma mediadora do conhecimento ecológico ao sistema social, buscando valorizar-se as espécies autóctones, a gestão dos recursos e a construção de uma melhor qualidade de vida, exigindo para isto que se formate estratégias de ações capazes de respeitá-la. A prática de cooperação revela-se assim como um instrumento de pressão geopolítica e de construção de um modelo de uso sustentável da biodiversidade.

O êxito desta pesquisa e a continuidade na mudança de paradigma do processo de partilhar conhecimento para a comunidade a partir da escola demandam tempo, para que haja percepção adequada do contexto que se apresenta, para melhor escolher instrumentos apropriados para a sua aplicação e para se tornar integrativa à comunidade 
alvo. Pode ser necessário longo prazo de admissão do projeto para permitir sua consciência crítica e a participação conjunta de instituições e outras representações locais em todas as suas fases. Deste modo, haverá uma oportunidade de amplas iniciativas para catalizar ações de conservação in situ dos recursos naturais. Ademais, através da reflexão, diálogo e participação de todos que se construirá uma sociedade do conhecimento honestamente inclusiva.

\section{Considerações finais}

C)

A análise em curso confirma as seguintes premissas para o segmento agricultura familiar:

Sensibilizar as instituições e seus grupos sociais, ao envolver o tema recursos naturais como bem coletivo. A experiência deve se integrar a populações de origem étnica e ancorada à diversas instituições de estrutura política social diversa., exige um avanço nas relações entre escola e comunidade.

A comunidade deve ser envolvida com projetos de sustentabilidade consoante com a educação ambiental. Este projeto é indissociável de outros de natureza social, para garantir o seu uso racional e sua proteção.

\section{Agradecimentos}

À Prefeitura de Angra dos Reis, ao corpo docente das escolas e a comunidade local pelo apoio e colaboração. Ao Instituto Estadual de Meio Ambiente (INEA) por conceder licença para esta pesquisa. Ao Conselho Nacional de Desenvolvimento Científico e Tecnológico $(\mathrm{CNPq})$ e a Fundação de Amparo à Pesquisa do Estado do Rio de Janeiro (FAPERJ) por prover recursos e bolsas de estudo.

\section{Referências Bibliográficas}

Alves Dos Santos, I. Comunidade, conservação e manejo: o caso dos polinizadores. Rev Tecnologia e Ambiente, v. 8, p.35-57, 2003.

CNAAA. Sistema de Meteorologia da Central Nuclear Almirante Álvaro Alberto Eletronuclear, 2005. 
Freire, P. À sombra desta mangueira. Olho d'água, 39ª Ed., São Paulo: Paz e Terra, 2004.

Guimarães, M. A Dimensão Ambiental na Educação. Campinas: $8^{\text {a }}$ Ed., Papirus Ed, 1995.

Mayers, N.; Mittermeier, R.A.; Mittermeier, C.G.; Fonseca, G.A.B. \& Kent, J.. Biodiversity hotspots for conservation priorities. Nature, v.403, p.853-858, 2000.

Oliveira, R.R. de. Ação antrópica e resultantes sobre a estrutura e composição da Mata Atlântica na Ilha Grande, Rio de Janeiro. Rodriguésia, v.53, n.82, p.33-58, 2002

Rocha, C.F.D., Bergallo, H.G., Alves, M.A.S. \& Van Sluys, M. A biodiversidade nos grandes remanescentes florestais do Estado do Rio de Janeiro e ns restingas da Mata Atlântica. São Carlos: RIMA Ed., 2003.

Tanizaki-Fonseca, K. \& Moulton, T.P. A fragmentação da Mata Atlântica no Estado do Rio de Janeiro e a perda da biodiversidade. In: Bergallo, G., Rocha, C.F.D, Alves, M.A.S. \& Van Sluys, M. Fauna ameaçada de extinção do Estado do Rio de Janeiro, Rio de Janeiro: EDUERJ, 2000. p. 23-36

Pereira, A.M.; Chaud Netto, J. Africanized honeybees: Biological characteristics, urban nesting behavior and accidents caused in Brazilian cities (Hymenoptera : Apidae).

Sociobiology, v.46, p.535-550, 2005

Santos da Silva, J.C; Lages, V.N. A meliponicultura como fator rde ecodesenvolvimento na área de proteção ambiental da Ilha de Santa Rita, Alagoas. Revista de Biologia e Ciências da Terra, v.1, n.3, p.1-5, 2001.

Becker, B. K. Amazônia: construindo o conceito e a conservação da biodiversidade na pratica. In: Garay, I; Dias, B. (Eds.) Conservação da biodiversidade em ecosssitemas. Petrópolis: Ed. Vozes, 2001. p 92-101

Aubertin, C. ; Alpha, A. ; Olivier, R. ; Lévêque, C. ; Verdeaux, F. ; Vivien, F.D. Côute Incrimental et protection de la biodiversite, Paris: Orstom, 1996.

Rodrigues, G.S. Impactos das atividades agrícolas sobre a Biodiversidade: Causas e conseqüências. In: Garay, I; Dias, B. Conservação da biodiversidade em ecosssitemas. Petrópolis: Ed Vozes, 2001. p 128-149.

Nogueira-Neto, P. Vida e Criação de Abelhas Indígenas sem ferrão. São Paulo: Edusp, 1997.

Leite, L.H.A. Pedagogia de projetos: intervenções no presente. Revista Presença Pedagógica, v.2, p.25-33, 1992.

Kerr, W. E. A importância da meliponicultura para o país. Biotecnologia, Ciência e Desenvolvimento, v.1, p.42-44, 1997. 
Kerr, W.E., Carvalho, G., A., Coletto da Silva, A.; Paiva de Assis, M. da G. Biodiversidade, pesquisa e desenvolvimento na Amazônia. Aspectos pouco mencionados da biodiversidade amazônica. Parcerias Estratégicas, v.12, p.20-41, 2001.

Vallejo, J.R. Conflitos territoriais em Parques Estaduais no Rio de Janeiro: uma avaliação à luz das políticas de Governo. Disponível em <http://www.feth.ggf.br/Parque.htm>. Acesso em 23/08/2008.

Venturieni, G.C.; Raiol, V. De F.O.; Pereira, C.A.B. Avaliação da introdução da criação racional de Melipona fasciculata (Apidae: Meliponina), entre os agricultores familiares de Bragança - PA, Brasil. Biota Neotropica, v.3, p.19-23, 2003. 